\title{
Mass changes in Arctic ice caps and glaciers: implications of regionalizing elevation changes
}

\author{
J. Nilsson ${ }^{1}$, L. Sandberg Sørensen ${ }^{1}$, V. R. Barletta ${ }^{1,2}$, and R. Forsberg ${ }^{1}$ \\ ${ }^{1}$ Department of Geodynamics, DTU Space, Technical University of Denmark, Elektrovej 327, 2800 Lyngby, Denmark \\ ${ }^{2}$ Ohio State University, 275 Mendenhall Lab, 125 S. Oval Mall, Columbus, Ohio, 43214, USA \\ Correspondence to: J. Nilsson (jnils@space.dtu.dk)
}

Received: 22 October 2013 - Published in The Cryosphere Discuss.: 11 December 2013

Revised: 27 November 2014 - Accepted: 2 December 2014 - Published: 27 January 2015

\begin{abstract}
The mass balance of glaciers and ice caps is sensitive to changing climate conditions. The mass changes derived in this study are determined from elevation changes derived measured by the Ice, Cloud, and land Elevation Satellite (ICESat) for the time period 2003-2009. Four methods, based on interpolation and extrapolation, are used to regionalize these elevation changes to areas without satellite coverage. A constant density assumption is then applied to estimate the mass change by integrating over the entire glaciated region.

The main purpose of this study is to investigate the sensitivity of the regional mass balance of Arctic ice caps and glaciers to different regionalization schemes. The sensitivity analysis is based on studying the spread of mass changes and their associated errors, and the suitability of the different regionalization techniques is assessed through crossvalidation.

The cross-validation results shows comparable accuracies for all regionalization methods, but the inferred mass change in individual regions, such as Svalbard and Iceland, can vary up to $4 \mathrm{Gt} \mathrm{a}^{-1}$, which exceeds the estimated errors by roughly $50 \%$ for these regions. This study further finds that this spread in mass balance is connected to the magnitude of the elevation change variability. This indicates that care should be taken when choosing a regionalization method, especially for areas which exhibit large variability in elevation change.
\end{abstract}

\section{Introduction}

The most recent assessments from the Intergovernmental Panel on Climate Change (Vaughan et al., 2014) and the
Snow, Water, Ice and Permafrost in the Arctic Assessment (AMAP, 2012) state that the mass loss from glaciers and ice sheets is a major contributor to sea-level rise. The use of satellite altimetry to determine the elevation change in the major ice sheets has been possible since the late 1980s and was pioneered by Zwally et al. (1987), Wingham et al. (1998) and others. In recent years this has been expanded to ice caps and glaciers using both satellite and airborne altimetry, in studies such as Gardner et al. (2011), Moholdt et al. (2010a, 2012), Abdalati et al. (2004) and Arendt et al. (2002, 2006).

The geodetic mass balance of glaciers or ice caps can be determined through the use of altimetry by measuring the temporal change in surface elevation of the glaciated area. This rate of change is then converted into volume and finally mass change by multiplying the rate of change by area and an assumed density scheme. Determining the regional rate of change in the entire glaciated area involves interpolation or extrapolation (referred to hereinafter as regionalization) of the elevation changes to unmeasured areas away from the satellite ground tracks. This regionalization might introduce a large uncertainty to the volume estimate, as the track coverage over individual ice caps and glaciers are usually limited.

The focus of this study is to determine the impact of different regionalization schemes on regional ice-mass balance estimates of Iceland, Svalbard, the Russian High Arctic and the Canadian Arctic (south and north). Studying the spread of mass change and their estimated errors allows us to judge the different regions' sensitivity to the regionalization procedure. A cross-validation allows us to identify more preferable regionalization schemes. 


\section{Study areas and data}

In this study, we focus on five regions in the Arctic: Iceland (ICEL), Svalbard (SVLB), the Russian High Arctic (RUS), Canadian Arctic North (CAN) and Canadian Arctic South (CAS). The glacier outlines for these areas have been obtained from the "Randolph Glacier Inventory" (RGI) (Pfeffer et al., 2014).

The regional mass changes have been estimated from elevation changes obtained from the Ice, Cloud, and land Elevation Satellite (ICESat) (Schutz et al., 2005) over the time period 2003-2009. ICESat carried the Geoscience Laser Altimetry System (GLAS), which operated from 2003 to 2009 and had a repeat cycle of 96 days with a 33-day sub-cycle. The system measured the range between the satellite and a surface on the Earth, derived from the delay time between the transmitted laser pulse and the received return echo. The average ground-track sample spacing was $172 \mathrm{~m}$ along-track, and the ground footprint was approximately $70 \mathrm{~m}$ in diameter. The ICESat elevation data are obtained from the National Snow and Ice Data Center (http://nsidc.org/data/icesat/index. $\mathrm{html}$ ) in the form of the GLA06 L1B global surface elevation data product, product release (R33).

Digital elevation models (DEMs) with a resolution of $1 \mathrm{~km}$ (30 arcsec) for use in the elevation-dependent regionalization are available for the five areas. The GTOPO30 DEM is used for the areas of CAS, CAN and RUS. For SVLB and ICEL, DEMs from the National Geospatial-Intelligence Agency (NGA) are used. The GTOPO30 model is estimated to have vertical accuracies of 50-200 m (http://www1.gsi.go.jp/ geowww/globalmap-gsi/gtopo30/gtopo30.html). The NGA DEMs have a similar accuracy, as the data partly have common roots.

To further estimate the quality of the topography models, we have compared them to 2003-2009 surface heights obtained from ICESat by interpolating the DEMs' surface heights to the ICESat data locations using bilinear interpolation. We estimate the standard deviation of the difference between the DEM heights and the ICESat heights to judge their quality. For the GTOPO30 model we find an average standard deviation over all regions of $\sim 65 \mathrm{~m}$ and for the NGA DEMs of $\sim 45 \mathrm{~m}$.

\section{Data processing}

In an initial step, the ICESat GLA06 product has been filtered using the quality flags and rejection parameters included in the product release. Several rejection criteria have been used in the data culling, e.g. data are only used if the flags indicated usable elevations (i_ElvuseFlg $=1$ ) and only have one peak in the return signal (i_numPk $=1$ ). Relevant data (i_satCorrFlg $=2$ ) have been corrected with the provided saturation correction. Each elevation measurement has been corrected for the Gaussian centroid (GC) offsets according to
Borsa et al. (2013). There exists an inter-campaign bias in the ICESat data Siegfried et al. (2011) and Hofton et al. (2013), but since this is still debated, we have not applied any bias correction in this study. The RGI glacier outlines have been used to extract only data over the glaciated areas of interest.

The ICESat ground tracks did not have perfect spatial repetition, and there could be large (up to $1^{\circ}$ ) offsets between the individual tracks from the main ground-track cluster. Tracks with large offsets have been edited out in order to produce more robust elevation change estimates. The ICESat repeat ground tracks are divided into $500 \mathrm{~m}$ segments to estimate surface elevation changes. The mean elevation change was estimated in each segment by least-squares regression if data from more than six campaigns were available. This method is described in detail in Sørensen et al. (2011) (referred to in that paper as the M3 method).

A cleaning procedure has been applied to the estimated elevation changes, in which elevation changes with an estimated standard deviation (estimated from the least-squares solution) outside the $95 \%$ confidence interval of the regression errors are removed. Furthermore, a 10-point moving Hampel filter (Pearson et al., 2002) has been used to identify and remove outliers in the elevation changes. The filtering is applied in the elevation change versus elevation domain to ease outlier detection. The success of the screening was judged visually to avoid unnecessary rejection. As a last step, an along-track smoothing filter has been applied to the elevation change data. An unweighted five-point moving average filter with a corresponding physical filter distance of $2.5 \mathrm{~km}$ has been used. Smoothing is undertaken to remove high-frequency noise from the elevation change estimates, and to aid the fitting procedure for the extrapolation and surface fitting for the interpolation methods, which are described in Sects. 4.2.1 and 4.2.2.

\section{Methods}

This study uses four different methods that have been implemented to regionalize elevation change to partly unmeasured glaciated areas. The four methods can broadly be divided into two categories: interpolation and extrapolation methods. The fundamental difference between the two approaches is what main correlation dependency they use for the regionalization procedure.

The interpolation methods use the spatial correlation (horizontal) of the elevation changes to predict an elevation change value at a specific geographical location. While the extrapolation method uses the usually high altitudinal correlation of elevation change to model the elevation change at a specific elevation. The four different methods (referred to as M1-M4), based on interpolation and extrapolation, can be summarized as follows: 
- M1: smooth surface fit,

- M2: spatial model,

- M3: hypsometric polynomial,

- M4: hypsometric elevation bins.

The methods introduced here will be explained in the following sections.

One of the main sources of uncertainty in the mass change estimation is the conversion to mass via a density assumption (Huss et al., 2013). A constant density of $900 \mathrm{~kg} \mathrm{~m}^{-3}$ is used in this study. This assumption has also been applied by others, such as Gardner et al. (2011) and Moholdt et al. (2010a, 2012), and has been used in this study to simplify comparisons to other studies and to ensure that the spread in the mass balance estimates is a result of the different regionalization schemes alone and not due to the density conversion.

\subsection{Regionalization: spatial interpolation}

The first regionalization method (referred to as M1) fits a smooth surface to the scattered elevation change estimates, with an along-track resolution of $500 \mathrm{~m}$, using least-squares collocation (as implemented in the GRAVSOFT program GEOGRID; see Forsberg et al., 2008, and Moritz., 1978) onto a regular grid, with a grid spacing of $0.01^{\circ}$ latitude and $0.025^{\circ}$ longitude, corresponding to a resolution of $\sim 1 \mathrm{~km}$. The glaciated area of these grids have then been extracted using the RGI glacier outlines.

The least-squares collocation interpolation uses a quadrant-based nearest-neighbour search to find the $N_{\mathrm{q}}$ closest points in every quadrant around the prediction point. The data points are then interpolated by applying a second-order Markov covariance model. The covariance length is found from the data and the correlation distance is input by the user to the GEOGRID program. The correlation length has been increased until the individual satellite ground tracks are not visible on the surface. This method create a smooth continuous surface between the individual ground tracks, that usually have large cross-track spacing.

Due to data processing and data editing there is a loss of spatial coverage and thus data gaps in the along-track elevation changes. The second regionalization method (referred to as M2) tries to improve this by re-sampling the along-track data location in every track from 500 to $100 \mathrm{~m}$. This to fill in data gaps and increases the along-track resolution. New along-track elevation changes are then estimated from the entire elevation change data set using the following model:

$\dot{h}=a_{0}+a_{1} \Phi+a_{2} \lambda+a_{3} h+\ldots+a_{N} h^{N}$,

where $\dot{h}$ is the parametrized elevation change value, $a_{i}$ are the model coefficients, $h$ is the DEM elevation, $N$ is the model order, $\Phi$ is the latitude and $\lambda$ is the longitude. The model order used for each region is the same as described in Sect. 4.1.2 for the spatial extrapolation methods. The M2 approach was chosen because it takes into account the overall spatial pattern of the elevation changes instead of just the nearest neighbours, which can in some cases be situated far away due to large across-track distances.

For the five regions of interest in this study, the number of points in each quadrant is set to $N_{\mathrm{q}}=5$, and a correlation length of $50 \mathrm{~km}$ gave a sufficiently smooth surface.

\subsection{Regionalization: hypsometric extrapolation}

The third regionalization method (M3) uses hypsometric averaging (Nuth et al., 2010; Moholdt et al., 2010a) for extrapolation of elevation change estimates to derive volume change. Hypsometric averaging is based on parametrizing elevation changes as a function of elevation using an external DEM, with the corresponding grid spacing as M1-M2. The glaciated area is divided into elevation bands or bins, and each band is assigned a representative elevation change value, estimated from the parametrized data set.

In M3, the elevation changes are parametrized by fitting a polynomial function to all the elevation change data, as in Nuth et al. (2010) and Moholdt et al. (2010a). The elevations are obtained from the glacier-masked DEMs for every region (see Sect. 2). Hypsometric averaging is then used to extrapolate the elevation changes regionally.

To determine the degree and the number of terms in the polynomial, we need a measure of how much variance the model is able to account for. The more variability that can be incorporated into the model, the better it will explain the underlying statistics of the measured data. We use the adjusted $R^{2}$ statistics as a measure of incorporated variance (see Moholdt et al., 2010a). The degree of the polynomial and the number of parameters are then increased until a convergence of this $R^{2}$ is reached. For all regions except Svalbard, a linear fit $(D=1)$ was sufficient to parametrize the relation. For Svalbard, a third-order polynomial $(D=3)$ fits the distribution best (as measured by $R^{2}$, as used by Moholdt et al., 2010a). An elevation bin range of $50 \mathrm{~m}$ was chosen for all regions, consistent with Gardner et al. (2011).

The fourth regionalization method (M4) also involves binning the elevation changes according to elevation (as in M3), but instead of estimating the centre bin elevation change from a continuous function we instead use the mean value of the elevation changes inside the bin. Elevation bins that do not contain any data are assigned a value from linear interpolation. DEM elevations which are not covered by the ICESat data (usually low and high elevations) are assigned a value from extrapolation of the linear function to these bins, estimated from the entire data set.

The Russian High Arctic was divided into three subregions (Novaya Zemlya, Franz Josef Land and Severnaya Zemlya) for the analysis when using regionalization methods M3 and M4, due to large geographical separation within this region. 


\subsection{Volume and mass change}

To determine the regional volume change in the interpolated and extrapolated fields the estimated elevation changes are multiplied by their corresponding area. This procedure differs between the inter and extrapolation methods and is for that reason described below.

To estimate the volume change from the interpolation methods (M1-M2) each individual elevation change grid cell (pixel), $\dot{h_{i}}$, is multiplied with its corresponding area, corresponding pixel area $A_{\mathrm{p}}$, and summed as follows to obtain the regional volume change $\dot{V}$ :

$\dot{V}=\sum\left(\dot{h_{i}}\right) \cdot A_{\mathrm{p}}$

The volume change from the extrapolated elevation changes (M3-M4) are estimated in a slightly different way. Here the estimated elevation change for each bin or band is multiplied with the total area of each band, and summed as follows to obtain the regional volume change:

$\dot{V}=\sum(\dot{h}(z) \cdot A(z))$

where $\dot{h}$ is the specific elevation change value assigned to the elevation band/bin $z$, which is defined as the centre or midelevation of that bin (i.e. $25 \mathrm{~m}$ if the bin range is $0-50 \mathrm{~m}$ ). $A(z)$ represents the total area inside the elevation band/bin at the specific binned elevation $z$.

The regional mass change is then estimated by multiplying the volume change by a constant density of $900 \mathrm{~kg} \mathrm{~m}^{-3}$. This approach assumes that the mass changes are due to effects such as ice melt and dynamic thinning while ignoring effects like changes in accumulation rate and firn densification. This is a very simplified view and is not always valid, which makes it a large source of uncertainty.

\section{Cross-validation}

A cross-validation scheme has been employed to assess the quality of the regionalized elevation change fields from the four different methods. As the individual elevation changes are highly correlated along-track, we perform a cross-validation scheme on entire ICESat tracks of elevation changes. The individual ground tracks are assumed to be uncorrelated, and the cross-validation is performed in the following manner:

1. Remove one of the ground tracks from the original data set.

2. Use M1-M4 to regionalize the elevation changes from the reduced data set.

3. Find the estimated elevation change values from the different methods at the locations of the removed ground track.
4. Compute the difference between the estimated and original elevation changes.

5. Compute the root mean square (rms) of the residuals.

6. Repeat the procedure for all available ground tracks.

This procedure will produce one rms value for each ground track and $N_{\text {rms }}$ for each method. The mean rms, $\overline{\mathrm{rms}}$, of all the ground tracks is then used to judge the quality of the different regionalization schemes.

\section{Error analysis}

We base the error analysis on two main concepts - the standard deviation around the mean and the standard error of the data - following the approaches of Nuth et al. (2010) and Moholdt et al. (2010a). Several studies have been dedicated to quantifying the individual point measurement errors for ICESat over ice-covered regions. Brenner et al. (2007) found that the ICESat measurement error over ice sheets varied as a function of surface slope, ranging from $0.14 \mathrm{~m}$ at $0.1^{\circ}$ up to $0.5 \mathrm{~m}$ at $1.2^{\circ}$. Regions such as Svalbard have a large range in surface slope, varying between 0 and $29^{\circ}$ at most, with a mean slope of $4.1^{\circ}$. Therefore, we assume a conservative error of $\varepsilon_{\text {icesat }}=0.17 \mathrm{~m} \mathrm{a}^{-1}$, coming from a measurement error of $1 \mathrm{~m}$ (Nuth et al., 2010) and a measurement period of 6 years. This error does not account for the inter-campaign bias present in the ICESat data, which does not affect the spread of the regional mass balance.

To estimate the error from the elevation change estimation procedure, we use the standard deviation estimated from the least-squares solution of the elevation changes as a measure of how trustworthy the individual elevation change measurements are (Sørensen et al., 2011). ICESat elevation changes are highly correlated along-track due to distance being short between the measurements, compared to variations in the topography. In this study, we have estimated the correlation length from the semi-variogram of the elevation changes, and use the correlation length to spatially bin the elevation changes. The correlation lengths for the five regions are found to be $\sim 15 \mathrm{~km}$ for SVLB, $\sim 10 \mathrm{~km}$ for ICEL, $\sim 20 \mathrm{~km}$ for CAN, $\sim 20 \mathrm{~km}$ for CAS and $\sim 10 \mathrm{~km}$ for RUS. For more detailed work on this topic, please see Rolstad et al (2009). The bins are then assumed to be uncorrelated, and the total number of non-empty bins is used to estimate the standard error, $\varepsilon_{\mathrm{d} h / \mathrm{d} t}$, for all four methods M1-M4:

$\varepsilon_{\mathrm{d} h / \mathrm{d} t}=\frac{\sigma_{\mathrm{d} h / \mathrm{d} t}}{\sqrt{N}}$

where $N$ is the number of uncorrelated bins and $\sigma_{\mathrm{d} h / \mathrm{d} t}$ is the mean standard deviation of the elevation changes. Here, $\sigma_{\mathrm{d} h / \mathrm{d} t}$ has already been reduced by a factor of $1 / \sqrt{N_{\mathrm{s}}}$ due to the along-track smoothing, with $N_{\mathrm{s}}$ being the size of the smoothing filter. 

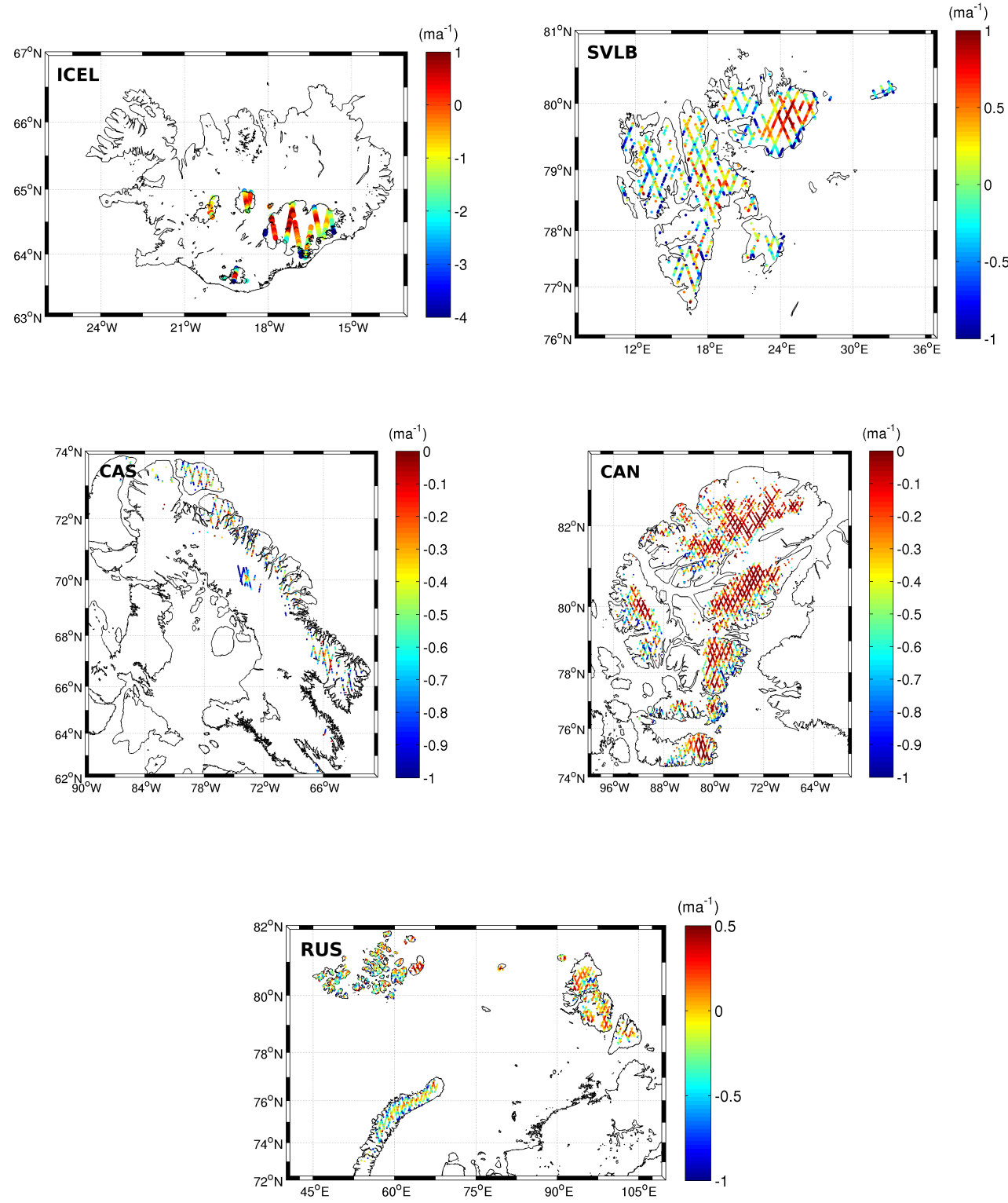

Figure 1. Spatial patterns of elevation changes of the five regions in the form of the satellite ground track coverage.

The least-squares collocation error associated with M1 and $\mathrm{M} 2$ is estimated by computing the standard deviation of the data around every prediction point according to Moritz. (1978). The mean value of these standard deviations is used as the interpolation error, and the standard error is computed in the same way as in the elevation change procedure:

$\varepsilon_{\text {int }}=\frac{\sigma_{\text {int }}}{\sqrt{N}}$,

where $\sigma_{\text {int }}$ is the mean standard deviation from the collocation prediction of the data inside the glaciated area.

We quantify the parametrization error from the fitting of the polynomial function used in M2 and M3 by calculating the root-mean-square error (RMSE) between the original el- evation change estimates and the predicted values:

$\varepsilon_{\mathrm{fit}}=\frac{\sigma_{\mathrm{fit}}}{\sqrt{N-D}}$,

where $\sigma_{\text {fit }}$ is the RMSE between the original and predicted data, and $\sqrt{N-D}$ is the adjustment due to the degree of the polynomial. The extrapolation error, $\varepsilon_{\text {ext }}$, relevant for method M3, is quantified by the same approach as used in Nuth et al. (2010), with the extrapolation error being the rootsum-square (RSS) difference of the fitted error minus the elevation change error:

$\varepsilon_{\mathrm{ext}}=\sqrt{\varepsilon_{\mathrm{fit}}^{2}-\varepsilon_{\mathrm{d} h / \mathrm{d} t}^{2}}$. 
Table 1. The number of error terms present in each method. These error are then combined into a height error using RSS.

\begin{tabular}{cl}
\hline Method & Error terms \\
\hline M1 & $\varepsilon_{\text {icesat }}, \varepsilon_{\text {int }}, \varepsilon_{\mathrm{d} h / \mathrm{d} t}$ \\
M2 & $\varepsilon_{\text {icesat }}, \varepsilon_{\text {int }}, \varepsilon_{\mathrm{d} h / \mathrm{d} t}, \varepsilon_{\text {fit }}$ \\
M3 & $\varepsilon_{\text {icesat }}, \varepsilon_{\mathrm{ext}}, \varepsilon_{\mathrm{d} h / \mathrm{d} t}$ \\
M4 & $\varepsilon_{\text {icesat }}, \varepsilon_{\mathrm{b}}, \varepsilon_{\mathrm{d} h / \mathrm{d} t}$ \\
\hline
\end{tabular}

The extrapolation error for the mean binning method is referred to as the binning error, $\varepsilon_{\mathrm{b}}$, not to be confused with $\varepsilon_{\text {ext }}$. This error is associated with M4 and is defined as the standard deviation inside every elevation bin, $\sigma_{\mathrm{b}}$. The standard error is then calculated by assuming that the individual bins are uncorrelated:

$\varepsilon_{\mathrm{b}}=\frac{\sigma_{\mathrm{b}}}{\sqrt{N}}$

The corresponding total elevation change error, $\varepsilon_{\text {tot }}$, is then estimated as the RSS of the individual error sources as given in Table 1 . The volumetric error, $\varepsilon_{\mathrm{vol}}$, can then be estimated by multiplying the elevation change error with the total glaciated area

$\varepsilon_{\mathrm{vol}}=\varepsilon_{\mathrm{tot}} \cdot A$

We also include an error term, $\varepsilon_{\rho}$, to account for the simple density assumption used that ignores the fact that density is actually a function of space and time. The approach follows that of, Moholdt et al. (2010b)

$\varepsilon_{\rho}=\frac{1}{2}\left(\rho_{\text {ice }}-\rho_{\text {firn }}\right)$,

where $\rho_{\text {ice }}$ and $\rho_{\text {firn }}$ are the densities of ice and firn, respectively. This error is applied to the entire glaciated region. Finally, we can estimate the mass balance error, $\varepsilon_{\text {mass }}$, as follows:

$\varepsilon_{\text {mass }}=\sqrt{\left(\varepsilon_{\mathrm{vol}} \cdot \rho\right)^{2}+\left(\dot{V} \cdot \varepsilon_{\rho}\right)^{2}}$,

where $\dot{V}$ is the estimated volume change.

\section{Results}

The along-track rates of elevation change have been derived for the five regions: ICEL, SVLB, CAS, CAN and RUS. The elevation change results are shown in Fig. 1. The regions exhibit different patterns of rates and variability in the elevation changes. To clarify these differences, a histogram of the elevation changes for the different regions is shown in Fig. 2, and the associated mean elevation change rate, standard deviation, and minimum and maximum values are presented in Table 2. ICEL shows the largest mean rate and variability in elevation change of all five regions, while RUS and
Table 2. ICESat point statistics of elevation change for the different Arctic regions. The values are in $\mathrm{ma}^{-1}$ for the statistics and $\mathrm{km}^{2}$ for the area, and $N$ is the number of observations.

\begin{tabular}{lccccrr}
\hline Region & Mean & SD & Min & Max & Area & $N$ \\
\hline SVLB & -0.04 & 0.70 & -6.70 & 2.20 & 33673 & 4613 \\
ICEL & -0.65 & 1.14 & -6.20 & 1.79 & 10989 & 851 \\
CAN & -0.27 & 0.34 & -3.00 & 1.44 & 103990 & 18022 \\
CAS & -0.58 & 0.42 & -3.75 & 1.88 & 40601 & 3281 \\
RUS & -0.13 & 0.34 & -2.00 & 1.46 & 51161 & 8797 \\
\hline
\end{tabular}

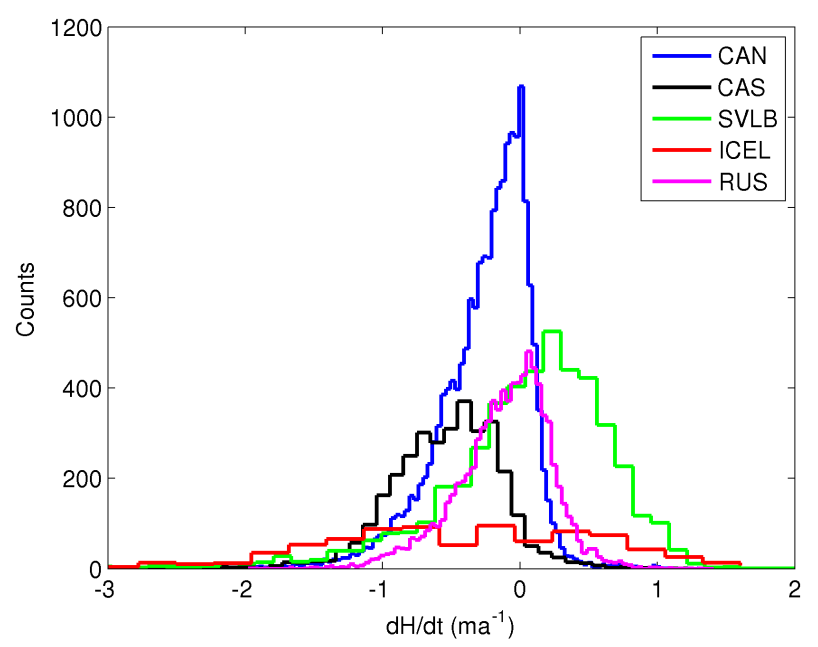

Figure 2. Histogram of elevation changes for the different Arctic regions. The Russian High Arctic (RUS) is treated as one region for visualization purposes.

CAN show the lowest variability. SVLB exhibits its own unique behaviour, with a more complex pattern of elevation change; compared to the other areas, SVLB shows the lowest mean rate of elevation change of $-0.04 \mathrm{~m} \mathrm{a}^{-1}$, and the second largest variability after Iceland. The variability in the elevation changes found in the Canadian Arctic and the RUS is a factor of 2 lower than in ICEL and SVLB. The rate of elevation change is apparently a function of latitude, with lowerlatitude regions like ICEL and CAS showing the largest mean rate of elevation change. This pattern is not as easily detected in the variability in the elevation change, seen in Table 2, where CAN and ICEL both show approximately the same magnitude of elevation change but a large difference in variability (63\%). Common for all five areas, though, is the negatively skewed distribution of elevation changes seen in Fig. 2.

The Arctic regions show a consistent pattern of large peripheral thinning and small changes in the interior regions of the ice caps (see Figs. 1 and 3). The thinning is mostly located in the low-elevation areas of the ice caps and glaciers $(h<500-800 \mathrm{~m})$, and becomes less negative as the elevation increases. This pattern has also been observed in both studies of ice sheets (e.g. Pritchard et al., 2009) and glaciers (Gardner et al., 2013; Bolsh 
et al., 2013). The lower elevations in every region show large variability in elevation change, which are clustered around the coastal regions, in areas such as CAN and CAS.

Figure 3 shows the elevation change estimates plotted as a function of elevation, together with the estimated DEM hypsometry and the ICESat elevations averaged per $50 \mathrm{~m}$ elevation bin. Most regions in Fig. 3 show no evident or significant sampling bias when comparing the ICESat heights and the estimated DEM hypsometry. There are, however, some observed discrepancies in the ICESat sampling for the low elevations in both ICEL and RUS.

The mass changes estimated from all four methods and all five regions in this study are presented in Table 3, which also contains the estimated mass change error and the mean RMSE from the cross-validation procedure for each method. From Table 3 it can be seen that for regions such as CAN, CAS and RUS, only a small spread in their mass balance estimates is observed. For these three regions, the spread in mass balance estimates is well within the bounds of the estimated errors. For ICEL and SVLB, the spread of the estimated mass changes from the different methods is on the order of $50 \%$ larger than the estimated mass change errors. The spread of the estimated mass changes for the different regions follows patterns seen in the elevation change variability (Table 2). Regions with high variability such as ICEL and SVLB show a much larger spread in the estimated mass changes than the areas with low elevation change variability.

The validity of the different regionalization schemes has been assessed though a cross-validation setup (Sect. 4.1.3). The results of the cross-validation are presented in Table 3, in the form of the mean, maximum and minimum rms for all four methods and regions. The mean RMSE follows the same pattern as detected in both the mass change estimates and elevation change variability, where areas associated with low elevation change variability and low spread in mass balance, such as CAN, CAS and RUS, show a much lower average rms $(\sim 65 \%$ lower) than ICEL and SVLB. ICEL shows on average the absolute highest RMSE and also the largest spread in rms between the different methods, as much as $20 \%$. For the other regions, the spread in the RMSE between the different methods show much better agreement, with observed differences of up to a few percent. The maximum and minimum values obtained from the cross-validation procedure show good agreement for most areas, such as CAN, CAS and RUS. For ICEL and SVLB, a larger spread is observed in these two parameters and follows in general the difference in mass balance, at least for SVLB.

Figure 4 shows the different spatial patterns obtained from the four regionalization procedures for ICEL. Here, the M3 and M4 methods show much larger negative elevation change values at lower elevations than the results based on M1 and M2. The more negative elevation change signal can also be detected in the estimated mass balance for M3 and M4, which is approximately $26 \%$ more negative than for M1M2.

\section{Discussion}

The large degree of variability seen in the lower elevations in Fig. 3 for most regions, especially RUS and CAN, indicates that complex spatial and temporal signals have been captured in the data (ice dynamics, ablation, snow accumulation, etc.). This variability is clustered into specific coastal areas in regions such as CAN and CAS, where most of the variability is located below $h<500-800 \mathrm{~m}$, and in areas with drainage systems. Most of the more negative elevation changes $\left(\dot{h}<-1.5 \mathrm{~m} \mathrm{a}^{-1}\right)$, on the tail of the elevation change distribution, are also located in these low-elevation areas.

This type of low elevation variability (excluding sampling biases) might help to explain the observed difference between the interpolation and extrapolation methods, seen in Table 3. The extrapolation methods have proven to produce more negative values in these area $(h<500-800 \mathrm{~m})$ than the interpolation methods, because the interpolation and extrapolation regionalization schemes have two fundamental differences: (i) interpolation methods assume a spatial correlation of the elevation changes and (ii) extrapolation methods assume a vertical correlation in elevation of the elevation changes.

The interpolation approach would in theory (with satisfactory spatial coverage) capture the local spatial variability better than the extrapolation methods, as the extrapolation methods contain no spatial information. The extrapolation methods, on the other hand, make use of the usually high correlation to elevation (if the region is homogeneous enough) to produce a model that in principle is more representative of the lower elevations, given no sampling bias, because the interpolation methods might use data further away from the prediction point. These data might be located at higher elevations or may not be a good representation of the overall glacier-wide pattern, depending on how far away the data points are.

The main issue to consider for the interpolation methods is the spatial coverage of the data. If the spatial coverage is dense enough, the interpolation will be able to capture the spatial pattern of the region. The main issue to consider for the extrapolation methods is the size of the area used for the parametrization. If the area used for the parametrization is too large, important behaviour of the elevation change pattern might not be accounted for in the model. The differences between the interpolation and extrapolation methods can be reduced by dividing the extrapolation region into sub-regions before parametrization, or by including a spatial dependency in the parametrization model.

The effect of the amount of spatial coverage and homogeneity of a region can be exemplified by CAN and ICEL. CAN, for example, shows a very low spread in mass balance 

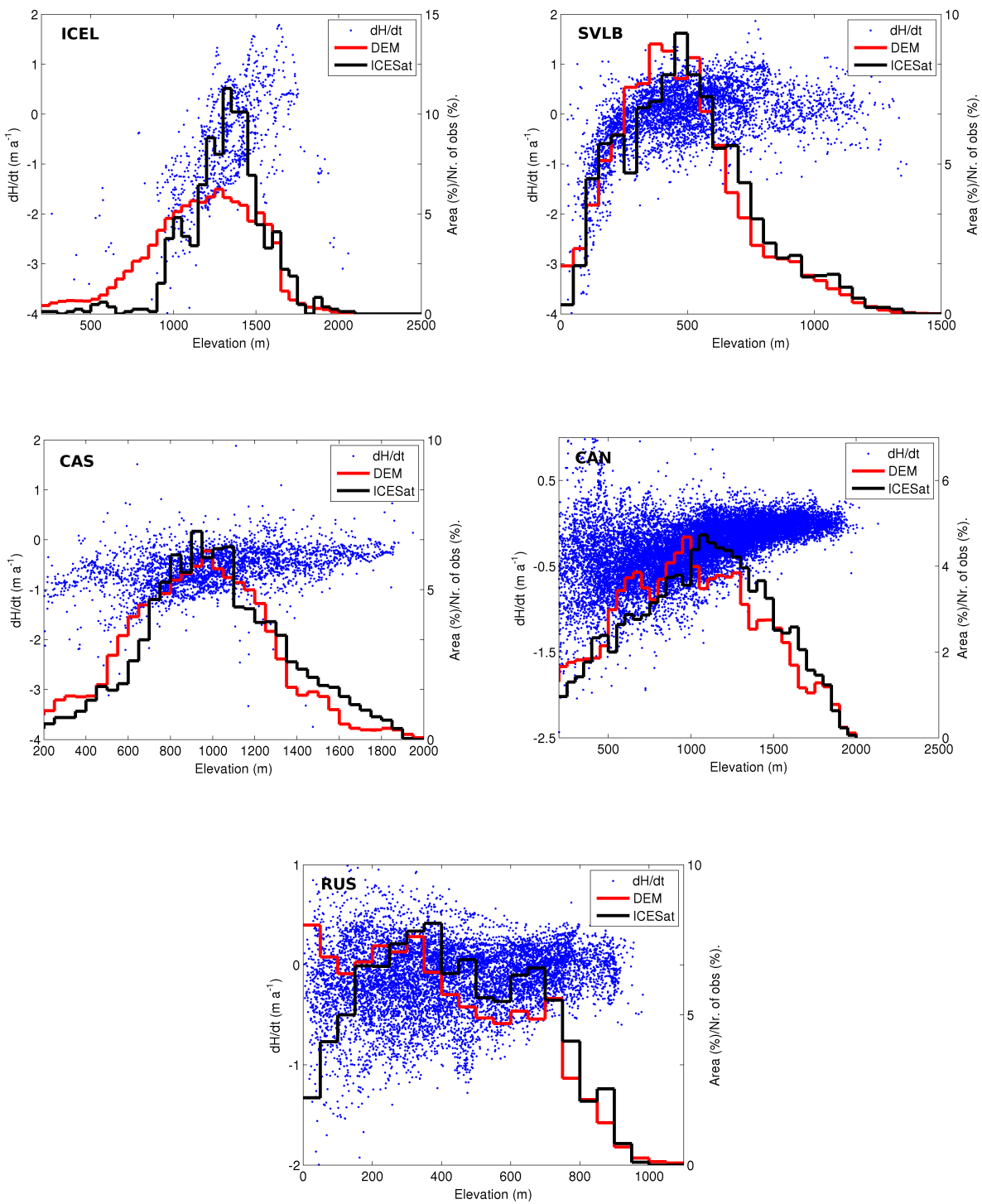

Figure 3. Elevation change (blue points) as a function of elevation for the different Arctic regions, which are used for the regional extrapolation. The black curve represents the density of ICESat's sampling and the red curve the DEM hypsometry, both per $50 \mathrm{~m}$ elevation bin.

compared to its large size, while ICEL shows a much larger spread in mass balance. This is due to the spatial sampling of the CAN region being dense and the elevation change variability low, compared to ICEL. This has the effect that both the interpolation and extrapolation methods can capture both the spatial and altitudinal patterns of elevation change for CAN, in contrast to, for example, ICEL with its low data density and large variability.

For most areas with a variability lower than $0.45 \mathrm{ma}^{-1}$ (see Table 2), the impact of the regionalization schemes on the spread of the mass balance is small (on the order of a few percent), with a corresponding spread that falls within the mass balance error. However, for areas with much higher spatial variability and magnitude of elevation change, like ICEL and SVLB, the effect is much more prominent (Table 3). This is most certainly connected to the different types of climate regimes that the regions exhibit. Regions like CAN, CAS and RUS have a continental climate regime (dry and cold), while ICEL and SVLB are in a more maritime climate regime (wet and warm).

For ICEL, the observed difference of almost $4 \mathrm{Gt} \mathrm{a}^{-1}$ most probably arises from the low-elevation under-sampling, seen in Fig. 3, where the extrapolation methods are forced to produce more negative elevation changes. This is clearly seen in Fig. 4, where the lower elevations of Vatnajökull produced from the extrapolation methods are much more negative than their interpolation counterparts, and in the mass balance results, presented in Table 3 . The estimated average 
Table 3. Geodetic mass balance $\dot{m}$ from the four methods with their corresponding errors $(\sigma)$, and their mean $\mathrm{rms}(\overline{\mathrm{rms}})$, maximum rms $\left(\mathrm{rms}_{\max }\right)$ and minimum $\mathrm{rms}\left(\mathrm{rms}_{\min }\right)$ from the cross-validation procedure.

\begin{tabular}{|c|c|c|c|c|c|c|}
\hline Region & Method & $\dot{m}\left[\mathrm{Gt} \mathrm{a}^{-1}\right]$ & $\sigma\left[\mathrm{Gta}^{-1}\right]$ & $\overline{\mathrm{rms}}\left[\mathrm{ma}^{-1}\right]$ & $\mathrm{rms}_{\max }\left[\mathrm{ma}^{-1}\right]$ & $\mathrm{rms}_{\min }\left[\mathrm{ma}^{-1}\right]$ \\
\hline \multirow{4}{*}{ Svalbard } & M1 & -3.3 & 2.5 & 0.57 & 3.45 & 0.17 \\
\hline & M2 & -5.0 & 2.7 & 0.59 & 2.76 & 0.26 \\
\hline & M3 & -2.5 & 1.6 & 0.59 & 4.10 & 0.18 \\
\hline & M4 & -0.5 & 2.5 & 0.57 & 4.10 & 0.22 \\
\hline \multirow{4}{*}{ Iceland } & M1 & -7.8 & 1.9 & 1.21 & 4.62 & 0.18 \\
\hline & M2 & -8.9 & 3.7 & 1.10 & 3.86 & 0.24 \\
\hline & M3 & -10.9 & 2.7 & 1.03 & 3.25 & 0.40 \\
\hline & M4 & -11.7 & 2.8 & 1.01 & 3.26 & 0.33 \\
\hline \multirow{4}{*}{$\begin{array}{l}\text { Canadian Arctic } \\
\text { North }\end{array}$} & M1 & -27.1 & 6.2 & 0.23 & 1.17 & 0.10 \\
\hline & M2 & -25.4 & 5.8 & 0.27 & 1.18 & 0.12 \\
\hline & M3 & -28.6 & 6.7 & 0.26 & 1.10 & 0.09 \\
\hline & M4 & -28.6 & 7.9 & 0.25 & 1.03 & 0.10 \\
\hline \multirow{4}{*}{$\begin{array}{l}\text { Canadian Arctic } \\
\text { South }\end{array}$} & M1 & -22.0 & 5.7 & 0.39 & 2.46 & 0.15 \\
\hline & M2 & -22.5 & 5.1 & 0.38 & 2.37 & 0.14 \\
\hline & M3 & -22.9 & 5.3 & 0.37 & 2.52 & 0.11 \\
\hline & M4 & -22.9 & 5.2 & 0.37 & 2.47 & 0.13 \\
\hline \multirow{4}{*}{$\begin{array}{l}\text { Russian High } \\
\text { Arctic }\end{array}$} & M1 & -7.1 & 2.0 & 0.25 & 0.79 & 0.04 \\
\hline & M2 & -6.4 & 1.9 & 0.27 & 0.81 & 0.07 \\
\hline & M3 & -7.7 & 3.1 & 0.28 & 0.88 & 0.10 \\
\hline & M4 & -7.1 & 3.9 & 0.29 & 0.87 & 0.09 \\
\hline
\end{tabular}
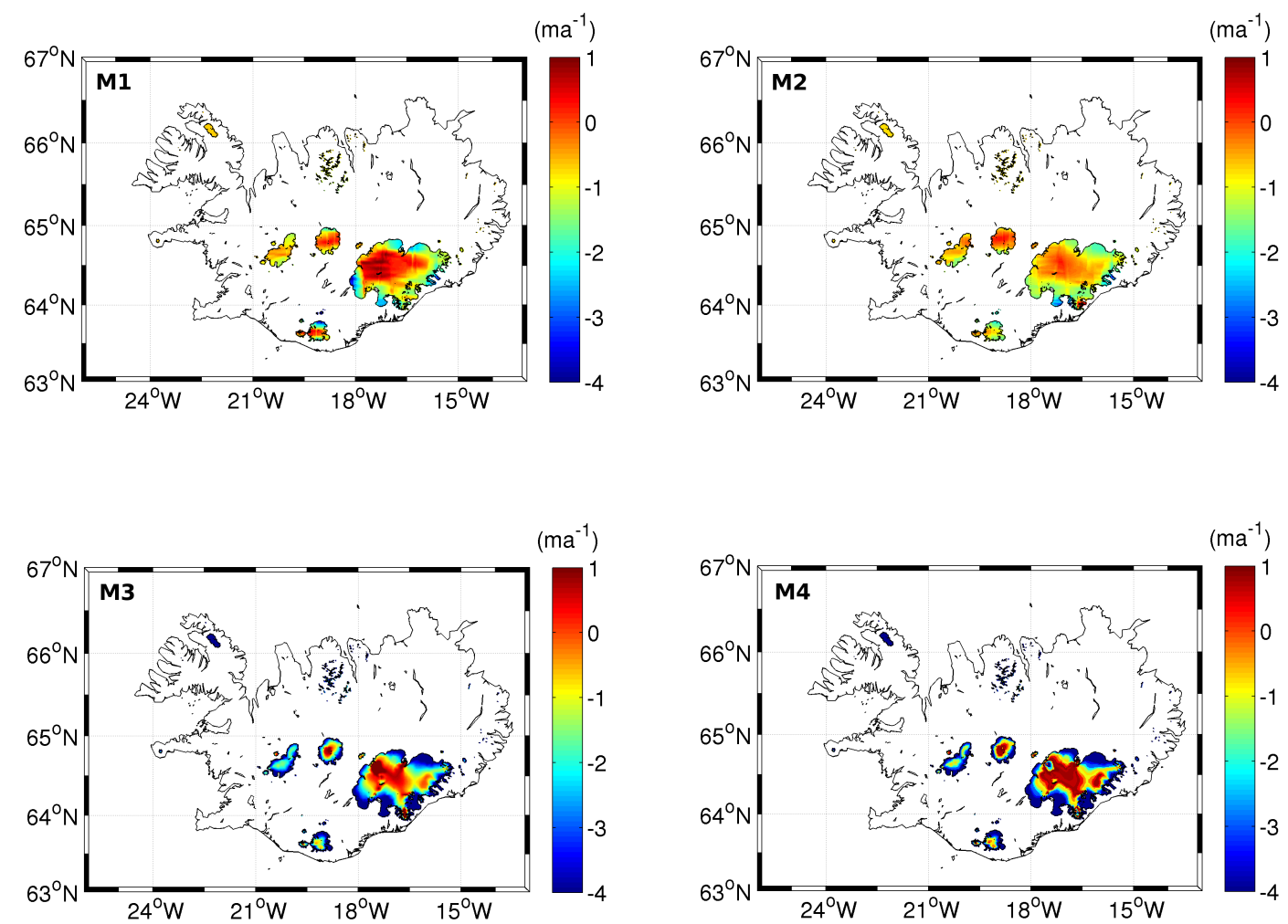

Figure 4. Regionalized elevation changes over Iceland from the M1-M4 methods showing the difference in estimated spatial patterns. 
mass balance for ICEL is $-9.8 \pm 2.8 \mathrm{Gta}^{-1}$ (average of all methods) agrees well with the average contemporary mass loss of $-10 \pm 1.8 \mathrm{Gt} \mathrm{a}^{-1}$ estimated by Björnsson et al. (2013) and Gardner et al. (2013) from glaciological measurements. However, there exists an average difference of roughly $25 \%$ between the interpolation and extrapolation methods, where the average of the interpolation methods $-8.35 \mathrm{Gta}^{-1}$ is more consistent with the results estimated by Gardner et al. (2013) of $-9 \pm 2 \mathrm{Gt} \mathrm{a}^{-1}$, while the average of the extrapolation methods $-11.3 \mathrm{Gt} \mathrm{a}^{-1}$ is more consistent with the results estimated by Björnsson et al. (2013) of $-11 \pm 1.5 \mathrm{Gt} \mathrm{a}^{-1}$.

The difference between the M1-M2 and M3-M4 methods observed in SVLB (Table 3) are most probably due to large spatial variability in the region. The regional parametrization of SVLB might not fully capture the local elevation change pattern as well as the interpolation methods. This effect can be mitigated by applying a spatial dependency, or by dividing the area into sub-regions, as previously discussed. The division into sub-regions has previously been done by Moholdt et al. (2010a), using the M3 method and a $900 \mathrm{~kg} \mathrm{~m}^{-3}$ density, yielding a mass balance of $-3.7 \mathrm{Gta}^{-1}$. This is in good agreement with the estimated mass balance of $-4.15 \mathrm{Gt} \mathrm{a}^{-1}$ obtained from this study by averaging the M1-M2 methods.

The estimated mass changes for CAS and RUS are on the same order as previous studies. Gardner et al. (2011) found a estimated mass loss for CAS of $-24 \pm 6 \mathrm{Gta}^{-1}$, while Moholdt et al. (2012) found a mass loss of $-9.8 \pm 1.9 \mathrm{Gta}^{-1}$ for RUS. Both results are in good agreement with the results obtained from this study of CAS of $-22.6 \pm 5.3 \mathrm{Gt} \mathrm{a}^{-1}$ and RUS of $-7.1 \pm 2.7 \mathrm{Gt} \mathrm{a}^{-1}$ by averaging methods M1M4. The estimated mass balance for CAN, however, shows a much larger difference of roughly $10 \mathrm{Gt} \mathrm{a}^{-1}$ compared to Gardner et al. (2011), who also used ICESat. This difference can mostly be explained by the fact that there was no intercampaign bias included in the elevation change estimation procedure. The exclusion of the inter-campaign bias gave an average mass balance for CAN of roughly $-30 \mathrm{Gta}^{-1}$. This was further reduced down to $-27.4 \mathrm{Gt} \mathrm{a}^{-1}$ when the GC offset correction (Borsa et al., 2013) was applied. As the GC offset scales with area, smaller regions are less affected by the offset, while larger regions will show a much larger difference. This is also what is observed in this study when applying the GC offset correction. The size of the mass correction introduced by the trend in the GC offset can be estimated for CAN to roughly $1.9 \mathrm{Gta}^{-1}$ by assuming a maximum trend value of $2 \mathrm{~cm} \mathrm{a}^{-1}$ and the area given in Table 2 . This value agrees well with the observed value of roughly $2.6 \mathrm{Gta}^{-1}$, which makes the GC offset an important correction for largescale mass balance studies using ICESat.

To determine whether the $1 \mathrm{~km}$ resolution is good enough to give realistic hypsometries, we made a comparison with the ASTER GDEM (http://gdem.ersdac.jspacesystems.or.jp) over Iceland. The ASTER GDEM was re-sampled at a $150 \mathrm{~m}$ resolution, to make it easier to handle; binned in $50 \mathrm{~m}$ elevation bands; and plotted against the NGA DEM for Ice-
Table 4. The final regional and total geodetic mass balance $\dot{m}$ estimated using the results from the cross-validation procedure and in situ comparison for Iceland, with corresponding error estimates $(\sigma)$.

\begin{tabular}{lccc}
\hline Region & $\dot{m}\left[\mathrm{Gt} \mathrm{a}^{-1}\right]$ & $\sigma\left[\mathrm{Gt} \mathrm{a}^{-1}\right]$ & Methods \\
\hline SVLB & -4.2 & 2.6 & M1, M2 \\
ICEL & -9.8 & 2.8 & M1-M4 \\
CAN & -27.4 & 6.7 & M1-M4 \\
CAS & -22.6 & 5.3 & M1-M4 \\
RUS & -7.1 & 2.7 & M1-M4 \\
\hline Total & -71.1 & 9.7 & \\
\hline
\end{tabular}

land over the glaciated areas. Iceland was chosen because the largest discrepancies between the regionalization methods were found here, and also because it exhibits the largest rate of and variability in elevation change. Even though there exists an apparent sampling bias, the calculated mass changes using the ASTER GDEM (methods M3-M4) gave only a total difference of $2 \%$. Thus we believe that the $1 \mathrm{~km}$ DEMs are of sufficient quality and resolution to give realistic hypsometries.

The results of the cross-validation procedure, seen in Table 3, indicate that, given enough data sampling, the interpolation and extrapolation methods produce regionalized elevation change estimates of the same quality. Therefore, the interpolation methods described in this study can be used for future mass balance studies in these and other areas even with relatively sparse data sampling. This finding is in contrast to previous discussion, such as that of in Moholdt et al. (2010a), which states that the spatial sampling would usually be to sparse to allow for spatial interpolation, which is definitely true on a sub-regional basis.

Using the estimated RMSEs from the cross-validation procedure, seen in Table 3, as a guide, a combined or final geodetic mass balance was computed, which can be seen in Table 4 . The final mass balance and corresponding mass error for CAN, CAS and RUS were determined using the average value of all four methods. Both the RMSE and the estimated mass balance error showed good individual agreement with each other. The final mass balance for SVLB was computed from the M1-M2 method, as these two methods showed the smallest range in the RMSE even though all four methods on average showed the same mean RMSE. Determining the final geodetic mass balance for ICEL is somewhat more arbitrary, as the low density of data points makes the cross-validation more difficult. However, here the average of all methods was chosen to determine the final mass balance of ICEL, as the average of M1-M4 shows the closest agreement with the average in situ-derived value of mass balance from Björnsson et al. (2013) and Gardner et al. (2013). 


\section{Conclusions}

In this study, we have determined the impact of different regionalization schemes of elevation changes on the estimated mass balance of five different Arctic regions. These five regions consisted of the Canadian Arctic (north and south), the Russian High Arctic, Svalbard and Iceland. The estimated mass balance was then, in combination with a crossvalidation procedure, used to determine how sensitive these regions are to different regionalization schemes of elevation change. Finally, we also estimated a mass balance budget for each region, using the results derived from the crossvalidation procedure and the estimated mass errors.

The study found that the mean rates of and variability in elevation change varied extensively over the different areas in the Arctic. The rate of elevation changes showed a range of $0.6 \mathrm{~m} \mathrm{a}^{-1}$ across the different regions, while the variability showed a corresponding range of $0.8 \mathrm{~m} \mathrm{a}^{-1}$. Regions with large variability in elevation change showed a large spread in the estimated mass changes from the different methods, given the described setup. This spread was on average $50 \%$ larger than the respective errors. For regions exhibiting low variability, the opposite was observed. Here, the spread of the mass changes lay well inside the estimated errors.

The statistics from the cross-validation procedure, in conjunction with the estimated mass balance results, indicate that the choice of regionalization method for regions with a variability of less than $0.5 \mathrm{~m} \mathrm{a}^{-1}$ is negligible. However, if the variability exceeds $0.5 \mathrm{~m} \mathrm{a}^{-1}$, caution and further analysis is required before choosing a method for mass balance studies. The results from the cross-validation further indicate that the interpolation and extrapolation methods are of the same quality for most areas. Hence the interpolation methods described in this study can also be used for mass balance studies of ice caps and glaciers with satisfactory results.

Acknowledgements. The authors would like to thank the different data contributors: the National Snow and Ice Data Center (NSIDC) for providing the ICESat data; the National Spatial-Intelligence Agency (NGA) for the Svalbard and Iceland DEM; the Ministry of Economy, Trade, and Industry (METI) of Japan and the United States National Aeronautics and Space Administration (NASA) for the ASTER GDEM; and the United States Geological Survey (USGS) for the GTOPO30 DEM. This publication is contribution no. 30 of the Nordic Centre of Excellence SVALI project "Stability and Variations of Arctic Land Ice", funded by the Nordic Top-level Research. We would like to thank the reviewers, especially Geir Moholdt, for their constructive comments and insights, which greatly improved this manuscript. This work was supported by funding from the ice2sea programme from the European Union 7th Framework Programme, grant number 226375. Ice2sea contribution number 175.

Edited by: E. Hanna

\section{References}

Abdalati, W., Krabill, W., Fredrick, E., Manizade, S., Martin, C., Sonntag, J., Swift, R., Thomas, R., Yungel, J., and Koerner, R.: Elevation changes of ice caps in the Canadian Arctic Archipelago, J. Geophys. Res., 109, F04007, doi:10.1029/2003JF000045, 2004.

AMAP: Arctic Climate Issues 2011: Changes in Arctic Snow, Water, Ice and Permafrost, SWIPA 2011 Overview Report, ISBN: 978-82-7971-073-8, 2012.

Arendt, A., Echelmeyer, K., Harrison, W., Lingle, C., and Valentine, V.: Rapid Wastage of Alaska Glaciers and Their Contribution to Rising Sea Level, Science, 297, 382-386, doi:10.1126/science.1072497, 2002.

Arendt, A. A., Echelmeyer, K., Harrison, W., Lingle, C., Zirnheld, S., Valentine, V., Ritchie, B., and Druckenmiller, M. Updated estimates of glacier volume changes in the western Chugach Mountains, Alaska, and a comparison of regional extrapolation methods, J. Geophys. Res.-Earth Surf., 111, F03019, doi:10.1029/2005JF000436, 2006.

Bamber, J., Krabill, W., Raper, V., and Dowdeswell, J.: Anomalous recent growth of part of a large Arctic ice cap: Austfonna, Svalbard, Geophys. Res. Lett., 31, L12402, doi:10.1029/2004GL019667, 2004.

Björnsson, H., Pálsson, F., Gudmundsson, S., Magnússon, E., Adalgeirsdóóttir, G., Jóóhannesson, T., Berthier, E., Sigurdsson, O., and Thorsteinsson, T.: Contribution of Icelandic ice caps to sea level rise: Trends and variability since the Little Ice Age, Geophys. Res., 40, 1-5, doi:10.1002/grl.50278, 2013.

Bolch, T., Sandberg Sörensen, L., Simonsen, S. B., Mölg, N., Machguth, H., Rastner, P., and Paul, F.: Mass loss of Greenland's glaciers and ice caps 2003-2008 revealed from ICESat laser altimetry data, Geophys. Res. Lett., 40, 875-881, doi:10.1002/grl.50270, 2013.

Borsa, A. A., Moholdt, G., Fricker, H. A., and Brunt, K. M.: A range correction for ICESat and its potential impact on ice-sheet mass balance studies, The Cryosphere, 8, 345-357, doi:10.5194/tc-8345-2014, 2014.

Brenner, A., DiMarzio, J. P., and Zwally, H. J.: Precision and Accuracy of Satellite Radar and Laser Altimeter Data Over the Continental Ice Sheets, IEEE Trans. Geosci. Remote Sens., 45, 321331, doi:10.1109/TGRS.2006.887172, 2007.

Forsberg, R. and Tscherning, C. C.: An overview manual for the GRAVSOFT Geodetic Gravity Field Modelling Programs, available at: http://www.gfy.ku.dk/ cct/publ_cct/cct1936.pdf (last access: 20 January 2015), 2008.

Gardner, A., Moholdt, G., Wouters, B., Wolken, G., Burgess, D., Sharp, M., Cogley, G., Braun, C., and Labine, C.: Sharply increased mass loss from glaciers and ice caps in the Canadian Arctic Archipelago, Nature, 473, 357-360, doi:10.1038/nature10089, 2011.

Gardner, A., Moholdt, G., Cogley, J. G., Wouters, B., Arendt, A., Wahr, J., Berthier, E., Hock, R., Pfeffer, W. T., Kaser G., Ligtenberg, S. R. M., Bolch, T., Martin, J., Sharp, M. J., Hagen, J. O., van den Broeke, M. R., and Paul, F.: A Reconciled Estimate of Glacier Contributions to Sea Level Rise: 2003 to 2009, Science, 340, 852-857, doi:10.1126/science.1234532, 2013.

Hofton, M. A., Luthcke, S. B., and Blair, J. B.: Estimation of ICESat intercampaign elevation biases from comparison of li- 
dar data in East Antarctica, Geophys. Res. Lett., 40, 852-857, doi:10.1002/2013GL057652, 2013.

Huss, M.: Density assumptions for converting geodetic glacier volume change to mass change, The Cryosphere, 7, 877-887, doi:10.5194/tc-7-877-2013, 2013.

Jacob, T., Wahr, J., Pfeffer, W. T., and Swenson, S.: Recent contributions of glaciers and ice caps to sea level rise, LETTER, Nature, 483, 514-518, doi:10.1038/nature10847, 2012.

Kaser, G., Cogley, J., Dyurgerov, M. B., Meier, M. F., and Ohmura, A.: Mass balance of glaciers and ice caps: Consensus estimates for 1961-2004, Geophys. Res. Lett., 33, L19501, doi:10.1029/2006GL027511, 2006.

Krabill, W., Abdalati, W., Fredrick E., Manizade, S., Martin, C., Sonntag, J., Swift, R., Thomas, R., Wright, W., and Yungel, J.: Greenland ice sheet: High elevation balance and peripheral thinning, Science, 289, 428-430, doi:10.1126/science.289.5478.428, 2000.

Moholdt, G., Nuth, C., Hagen, J. O., Kohler, J.: Recent elevation changes of Svalbard glaciers derived from ICESat laser altimetry, Remote Sens. Environ., 114, 2756-2767, 2010a.

Moholdt, G., Hagen, J. O., Eiken, T., and Schuler, T. V.: Geometric changes and mass balance of the Austfonna ice cap, Svalbard, The Cryosphere, 4, 21-34, doi:10.5194/tc-4-21-2010, 2010.

Moholdt, G., Wouters, B., and Gardner, A.: Recent mass change of glaciers in the Russian High Arctic, Geophys. Res., 39, L10502, doi:10.1029/2012GL051466, 2012.

Moritz, H.: Least Squares Collocation, Reviews of Geophysics and Space Physics, 16, 421-430, doi:10.1029/RG016i003p00421, 1978.

Nuth, C., Moholdt, G., Kohler, J., Hagen, J. O., and Kääb, A.: Svalbard glacier elevation changes and contribution to sea level rise, J. Geophys. Res., 115, F01008, doi:10.1029/2008JF001223, 2010.

Pearson, K. R.: Outliers in process modeling and identification, IEEE, Transa. Control Syst. Technol., 10, 55-63, doi:10.1109/87.974338, 2002.

Pfeffer, T.W., Arendt, A. A., Bliss, A., Bolch, T., Cogley, J. G., Gardner, A. S., Hagen, J. O., Hock, R., Kaser, G., Kienholz, C., Miles, E. S., Moholdt, G., Mölg, N., Paul, F., Radić, V., Rastner, P., Raup, B. H., Rich, J., Sharp, M. J.: The Randolph Consortium, J. Glaciol., 221, 537-552, doi:10.3189/2014jog13j176, 2014.
Pritchard, H. D., Arthern, R. J., Vaughan, D. G., and Edwards, L. A.: Extensive dynamics thinning on the margins of the Greenland and Antartic ice sheets, Nature, 7266, 971-975, doi:10.1038/nature08471, 2009.

Rolstad, C., Haug, T., and Denby, B.: Spatially-integrated geodetic glacier mass balance and its uncertainty based on geostatistical analysis: application to the Western Svartisen ice cap, Norway, J. Glaciol., 55, 666-680, 2009.

Schutz, B. E., Zwally, H. J., Shuman, C. A., Hancock, D., and DiMarzio, J. P.: Overview of the ICESat Mission, Geophys. Res. Lett., 32, L21S01, doi:10.1029/2005GL024009, 2005.

Siegfried, M. R., Hawley, R. L., and Burkhart, J. F.: High-resolution ground-based GPS measurements show intercampaign bias in ICESat elevation data near summit, Greenland, IEEE, Geosci. Remote Sens., 9, 3393-3400, doi:10.1109/TGRS.2011.2127483, 2011.

Sørensen, L. S., Simonsen, S. B., Nielsen, K., Lucas-Picher, P., Spada, G., Adalgeirsdottir, G., Forsberg, R., and Hvidberg, C. S.: Mass balance of the Greenland ice sheet (2003-2008) from ICESat data - the impact of interpolation, sampling and firn density, The Cryosphere, 5, 173-186, doi:10.5194/tc-5-173-2011, 2011.

Vaughan, D. G., Comiso, J. C., Allison, I., Carrasco, J., Kaser, G., Kwok, R., Mote, P., Murray, T., Paul, F., Ren, J., Rignot, E., Solomina, O., Steffen, K., and Zhang, T.: Observations: Cryosphere, in: Climate Change 2013: The Physical Science Basis. Contribution of Working Group I to the Fifth Assessment Report of the Intergovernmental Panel on Climate Change, edited by: Stocker, T. F., Qin, D., Plattner, G.-K., Tignor, M., Allen, S. K., Boschung, J., Nauels, A., Xia, Y., Bex, V., and Midgley, P. M., Cambridge University Press, Cambridge, UK and New York, NY, USA, 2013.

Wingham, D., Ridout, A., Scharroo, R., Arthern, R., and Shum, C. K.: Antartic elevation change from 1992-1996, Science, 282, 456-4458, doi:10.1126/science.282.5388.456, 1998.

Zwally, H. J., Bindschadler, R. A., Major, J. A., and Brenner, A. C.: Ice measurements by Geosat radar altimetry, Johns Hopkins APL Technical Digest (ISSN 0270-5214), Vol. 8, April-June, 251254, 1987. 